\title{
Postoperative analgesia: a comparison of intravenous on-demand fentanyl with epidural bupivacaine
}

\author{
W D WHITE, D J PEARCE，J NORMAN
}

British Medical fournal, 1979, 2, 166-167

\section{Summary and conclusions}

In a randomised trial postoperative pain relief was provided by either epidural injections of bupivacaine or an infusion of fentanyl adjusted by the patient to achieve adequate pain relief. Both techniques produced satisfactory analgesia without respiratory depression after peripheral arterial surgery.

The technique of infusing intravenously a potent analgesic in a dose adjusted by the patient appears to offer several advantages in postoperative care.

\section{Introduction}

Postoperative pain relief is often inadequate. ${ }^{1}$ Conventional prescriptions of opiates to be given "as required" rarely produce a consistent level of analgesia and often leave the patient in severe pain. Repeated epidural injections of local anaesthetics ${ }^{2}$ can produce adequate pain relief while increasing the mobility of the patient and decreasing postoperative pulmonary complications. The introduction of bupivacaine, with its longer duration of action, has made this type of analgesia popular, but its use demands increased surveillance of the patient to detect and treat complications such as hypotension. Some degree of motor blockade may occasionally accompany the sensory and autonomic block and cause further problems.

Rosen $e t a l^{3}$ have developed a demand system to deliver pethidine intravenously at the patient's request. The results in women in labour show that safe, acceptable levels of analgesia can be achieved. Hull ${ }^{4}$ designed a more complex system that can deliver any potent analgesic intravenously, and Janssen Pharmaceuticals are marketing a development of this that can combine constant infusion with demand doses. In this study we have compared the analgesia after vascular surgery produced by epidural injections of bupivacaine and by fentanyl given intravenously by a Janssen (JSI 0299) demand analgesia computer.

\section{Patients and methods}

Eighteen men and two women undergoing major peripheral vascular surgery were randomly divided into two groups comparable in age and weight. All were anaesthetised similarly: after premedication with papaveretum and hyoscine anaesthesia was induced with thiopentone and maintained with nitrous oxide and oxygen. Intermittent positive-pressure ventilation was maintained using pancuronium as the relaxant, and anaesthesia was supplemented with fentanyl and occasionally droperidol and halothane. A urinary catheter was inserted in each patient before surgery. At the end of the operation the neuromuscular block was antagonised with neostigmine and any respiratory depression from the analgesics with naloxone. All patients

\footnotetext{
Shackleton Department of Anaesthetics, General Hospital, Southampton SO9 4XY

W D WHITE, MB, FFARCS, senior registrar

D J PEARCE, MB, FFARCS, consultant

J NORMAN, PHD, FFARCS, professor
}

were breathing spontaneously on admission to the recovery ward. Blood pressure, heart rate, central venous pressure, urine output, conscious level, and respiratory rates were recorded by the nursing staff. All patients were given intravenous infusions, and none received food, drink, or medication by mouth during the study.

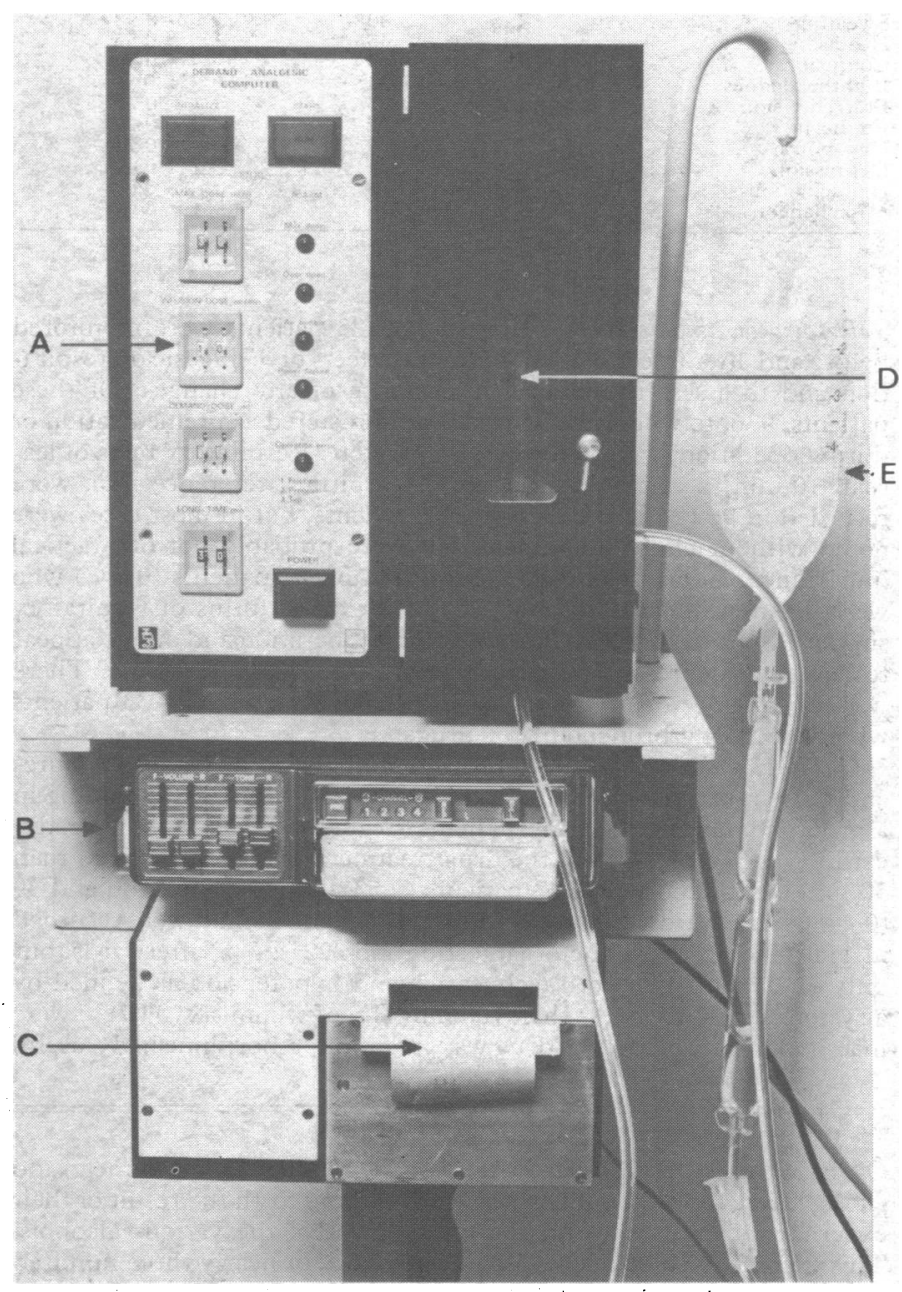

Janssen (JSI 0299) demand analgesia computer.

$A=$ Control box. $B=$ Cassette recorder. $C=$ Printout. $D=$ Constant infusion pump. $E=$ Infusion bag containing fentanyl in normal saline.

Epidural analgesia-Before the operation a catheter was placed in the lumbar epidural space; this was not used until after the operation, when epidural injections of $6-14 \mathrm{ml}$ bupivacaine $(0.375 \%)$ were given at two- to five-hourly intervals depending on the patient's pain. The first epidural injection was given by the anaesthetist, at a dosage that he judged to be adequate. Further injections were given by the nursing staff.

Fentanyl analgesia-Fentanyl, $2500 \mu \mathrm{g}$, was added to $500 \mathrm{ml}$ of saline to give a solution of $5 \mu \mathrm{g} / \mathrm{ml}$. The analgesic computer (figure) functions in three ways. Firstly, it may be set as a constant intravenous infusor; we set it to deliver $30 \mu \mathrm{g}$ of fentanyl/h. Secondly, at intervals predetermined by the anaesthetist (in our case between 20 and 90 minutes) it asks via a cassette recorder and loudspeaker whether the patient is in pain. If he is, he responds by pressing a thumb switch, which causes an additional injection of fentanyl to be given (in this 
study either 10 or $15 \mu \mathrm{g}$ ). Two minutes later the question is repeated, and up to four "demand" doses may be given in an eight-minute period. Finally, the patient can start the demand system by pressing the thumb switch at other times. The anaesthetist can set an overall maximum limit to how much fentanyl is given in any hour (we set a limit of $150 \mu \mathrm{g} / \mathrm{h}$ ), and safety cut-outs stop the delivery if a power failure occurs or air is present in the intravenous line. A printer records the initial settings and the amount of drug administered each 10 minutes. Fentanyl may therefore be delivered by a combination of constant infusion and demand delivery.

Evaluation of pain-Both systems were used to relieve pain for the first night after operation. Next morning, before the pain relief was discontinued, each patient assessed his impressions of the worst pain he had felt and the overall pain using $10-\mathrm{cm}$ analogue score lines. ${ }^{5}$ These consisted of unmarked horizontal $10-\mathrm{cm}$ lines. The patient was told that the left-hand end represented no pain and the righthand end represented the worst pain imaginable. He was asked to draw a vertical line through the horizontal to show the worst pain he had suffered and the pain overall. In addition, an arterial blood sample was withdrawn while the patient was breathing air and analysed for $\mathrm{pH}$ and tensions of carbon dioxide and oxygen using a Radiometer ABL 1 blood-gas analyser.

Statistical analysis-The pain scores were compared using a Wilcoxon two-sample rank test; other comparisons were made using Student's $t$ test.

\section{Results}

Epidural analgesia-No episodes of hypotension occurred in the patients who received epidural analgesia. The extent of the sensory block was not measured, but the first dose given by the anaesthetist was checked as being effective. This dose was repeated by the nursing staff when the patient complained of pain.

Fentanyl analgesia-Table I shows how much fentanyl was used.

TABLE I-Details of fentanyl dosages given by constant infusion and on demand

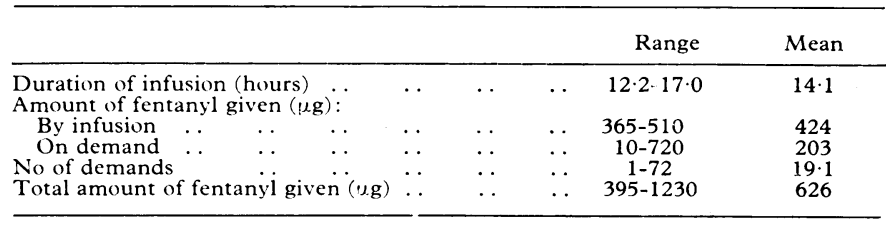

All patients were given a baseline infusion of $30 \mu \mathrm{g} / \mathrm{h}$. The number of demand doses varied from one to 72 , with a mean of 19 . On average the patients administered about $50^{\circ}$ o more fentanyl than was given by constant infusion, although one patient needed two and a half times as much.

Pain scores-The average overall pain scores were 2.08 in the patients who received fentanyl and 2.66 in those who received epidural analgesia. Individual scores were $0.4,1 \cdot 1,1 \cdot 2,1 \cdot 4,1 \cdot 5$, $1 \cdot 6,2 \cdot 8,3 \cdot 0,4 \cdot 1$, and $4 \cdot 4$ respectively in the fentanyl group and $0,0 \cdot 2,0 \cdot 3,0 \cdot 8,2 \cdot 2,2 \cdot 5,2 \cdot 7,3 \cdot 3,6 \cdot 5$, and $8 \cdot 1$ respectively in the epidural group. The score for the worst pain experience varied between 0.9 and 9.7 (mean 5.36) in the fentanyl group and between 0.5 and 9.3 (mean 5.56) in the epidural group. There were no significant differences in the overall and worst pain scores between the two groups.

Blood-gas analysis-The results of the blood-gas analysis with the patients breathing air were comparable in both groups (table II). No patient showed signs of respiratory depression as indicated by

TABLE II-Results of arterial blood-gas analysis during postoperative analgesia delivered by either fentanyl infused intravenously or epidural injections of bupivicaine. Figures are means (and ranges)

\begin{tabular}{|c|c|c|}
\hline & $\begin{array}{l}\text { Fentanyl } \\
\text { group }\end{array}$ & $\begin{array}{c}\text { Epidural } \\
\text { group }\end{array}$ \\
\hline $\begin{array}{l}\text { Oxygen tension }(\mathrm{kPa}) \\
\text { Carbon dioxide tension }(\mathrm{kPa}) \\
\mathrm{pH}\end{array}$ & $\begin{array}{c}8 \cdot 4(6 \cdot 7-9 \cdot 5) \\
5 \cdot 1(3 \cdot 7-6 \cdot 4) \\
7 \cdot 43(7 \cdot 36-7 \cdot 53)\end{array}$ & $\begin{array}{c}9 \cdot 2(7 \cdot 1-13 \cdot 2) \\
5 \cdot 1(4 \cdot 7-5 \cdot 9) \\
7 \cdot 44(7 \cdot 39-7 \cdot 49)\end{array}$ \\
\hline
\end{tabular}

Conversion: SI to traditional units-Arterial oxygen and carbon dioxide: $1 \mathrm{kPa} \approx 7.5 \mathrm{~mm} \mathrm{Hg}$. an increased carbon dioxide tension, and the oxygen tensions were normal for such patient.

\section{Discussion}

The postoperative pain relief produced by both the epidural injection of bupivacaine and the infusion of fentanyl was effective. Using a similar linear analogue score to that in our study analgesia produced by papaveretum prescribed "as necessary" led to much less adequate pain relief, giving overall pain scores of about $6 \cdot 7 .{ }^{6}$ The overall pain scores of patients who received fentanyl were grouped mainly at the bottom of the scale between 0.4 and $4 \cdot 1$, while those in the epidural group were grouped mainly at the lower end but with two stray results at 6.5 and $8 \cdot 1$. These two results show inadequate pain relief, which may have been because the catheter was misplaced or because the amount of bupivacaine injected was insufficient. Although the epidural was topped up at regular intervals, or more frequently if demanded, the patient did not have the same control over his own pain relief as with the fentanyl infusion and demand system.

Fears have been expressed that fentanyl causes postoperative respiratory depression, ${ }^{7}$ but this was not seen in our study. Both groups of patients were carefully monitored, and the respiratory rates did not decrease greatly in either. The lack of respiratory depression was borne out by the absence of increased carbon dioxide tensions. We believe that the fentanyl infusion is safe for wider use.

The demand analgesic computer may be useful on occasions when epidural analgesia cannot be used. Firstly, local anaesthetic techniques cannot be used at some sites for postoperative pain relief on a prolonged basis owing to the position of the wound. Secondly, an epidural catheter sometimes cannot be inserted because of anatomical abnormalities, local sepsis, previous spinal surgery, or the use of concurrent anticoagulant treatment. The more effective control of pain achieved by the intravenous route of administration is possible because adequate blood concentrations of analgesic are maintained. ${ }^{8}$ In addition, pain varies with iactors such as awareness and movement. The ability of the patient to set his own blood concentration with a potent, fast-acting agent may help him greatly.

In neither group was postoperative mobility affected, as the longest duration of study was 17 hours and patients who have undergene major vascular surgery in this unit are not routinely mobilised until the second postoperative day.

Epidural blockade is said to increase peripheral vascular dynamics; this is probably not solely due to sympathetic blockade but also to sensory blockade and relief of pain. ${ }^{9}$ In this study we did not measure peripheral blood flow, but we gained no clinical impression of any difference between the two groups. This may partly have been because good analgesia was provided by both methods.

We thank $\mathrm{Mr} \mathrm{J} \mathrm{H} \mathrm{H} \mathrm{Webster} \mathrm{for} \mathrm{permission} \mathrm{to} \mathrm{study} \mathrm{patients} \mathrm{in}$ his care; nursing staff of the recovery ward at the Royal South Hants Hospital; the department of teaching media; and Mrs R Sealey for secretarial help.

\section{References}

${ }^{1}$ British Medical fournal, 1978, 2, 517.

2 Spence, A A, and Logan, D A, British fournal of Anaesthesia, 1975, 47, suppl, p 281 .

3 McCarthy, J P, et al, IERE Conference Proceedings, No 34, 1976.

${ }^{4}$ Hull, C J, personal communication.

${ }^{5}$ Revill, S I, et al, Anaesthesia, 1976, 31, 191.

${ }^{6}$ Norman, J, unpublished results.

7 Adams, A P, and Pybus, D A, British Medical fournal, 1978, 1, 278.

${ }^{8}$ Stapleton, J V, Austin, K L, and Mather, L E, British Medical fournal, $1978,2,1499$.

9 Cousins, M J, and Wright, C J, Surgery, Gynecology and Obstetrics, 1971, 133, 56.

(Accepted 7 fune 1979) 